\title{
THE NATURE OF THE CONCEPT IN PROFESSIONAL COMMUNICATION
}

\author{
Oksana I. Aleshina \\ oksana.aleshina@tsput.ru \\ Yekaterina A. Korableva \\ eakorableva@mail.ru
}

\author{
Tula State Lev Tolstoy Pedagogical University (Tula, Russia)
}

\begin{abstract}
This paper is devoted to the research of the notion "concept" from the perspective of professional discourse. The aim of the paper is to analyze the nature, structure and use of the concept. To reveal the specificity of the concept, the authors study different points of view and definitions of the concept based on research of both Russian and foreign scholars. Much attention is paid to the problem of distinguishing three different terms - the concept, the conception and the meaning. Basic cognized features of these phenomena are analyzed. The authors come to the conclusion that concepts do not have an ethno-cultural specificity, but basic cognized features of the all concepts have a value component.
\end{abstract}

Key words: concept, meaning, sign, conception, definition, professional communication

\section{INTRODUCTION}

The term "concept" is the core term of the conceptual construct of cultural linguistics. Its fundamental, multi-aspect study involves the obligatory appeal of scientists to the analysis of different levels of the language using various research techniques. This level is considered to be the most important for the spiritual culture of a person, and reflects the value system of the society, the system of its moral, ethical and aesthetic preferences illustrating the peculiarities of the mentality of a particular linguistic and cultural community.

This article sets the following missions:

1. to justify the use of the term "concept", its difference from the terms "conception" and "meaning";

2. to describe the structure and the components of the "concept" and the criteria which are necessary for the recognition of the concept in text;

3. to define the classification of the concept.

The cognitive linguistics is a relatively new direction in the linguistics that studies the role of the language in the world categorizing. The definition of the concept is a key component in the cognitive science and a relatively new science of conceptology.

The term "concept" has currently been going through an era of "linguistic Renaissance" since the early 90 s of the $20^{\text {th }}$ century, primarily due to the scientific works of D. Likhachev and $\mathrm{Yu}$. Stepanov, who revived it and gave it a detailed interpretation. This term is used in the cognitive linguistics, in the paradigm of the linguistic conceptualism is explained by the introduction of the missing cognitive "link" in their categorical construct. Its content in addition to the concept includes the associative assessment and the representation of both its producers and users.

The problem of describing the essence of the concept remains relevant for the modern linguistic science. The system of concepts forms the worldview, which reflects the human understanding of the reality. The world we live in is not the world of objects but rather the world of concepts we have created for our intellectual, spiritual and social needs. 


\section{THE DEFINITION AND THE MAIN CHARACTERISTICS OF THE CONCEPT}

The definition of the concept is a key component in the cognitive linguistics. However, despite the fact that the definition of the concept was established long ago in the modern cognitive science, the understanding of the nature of this concept varies significantly in the concepts of different scientific schools and scientists.

By the end of the $20^{\text {th }}$ century, linguists realized that a native speaker is a carrier of certain conceptual systems. Concepts are mental entities. Each concept brings together fundamentally important human knowledge about the world [Trask, 1998].

The definition of the concept has been thoroughly studied in both Russian and foreign linguistics. Since the cognitive linguistics is a science originated in the United States, the first definitions of the concept were given by American scientists.

G. Lacoff, a researcher in cognitive linguistics, studies concepts as units that structure people's feelings and their relationship with each other, as they play an important role in determining the realities of everyday life. According to the theory of G. Lacoff, conceptual structures are developed on the basis of image schemes and were created as a result of human interaction with the physical world. In addition to image schemes, there is another type of concepts, "concepts of the basic level - this is the level where a single mental image can reflect the entire category" [Lacoff, 1980].

The system of concepts forms a picture of the world, which reflects a person's understanding of reality, its special conceptual "image", on the basis of which a person thinks the world. According to D. Geeraerts, a researcher in the field of the cognitive linguistics, there are 2 main approaches to understanding the concept: the concept reveals the nature of the conception, and the conception is the synonym of the meaning [Geeraerts, 2007].

$\mathrm{V}$. Telia finds the relation of the concept with the culture in the human consciousness. On the other hand, the concept is the link between an ordinary person, who is not the creator of cultural values, and the culture. V. Telia understands the concept as the connection of all the knowledge about the object, giving the following definition of the concept - the concept is the knowledge structured in the frame, which means that it reflects the essential features of the object [Telia, 1996].

The frame is a model of the cultural knowledge arrangement around a concept. It means that the knowledge of the world is associated with a particular language unit. In linguocultural texts the concept is a verbalized cultural meaning, and it is a semantic unit of the cultural language. In this approach, much attention is paid to the cultural aspect. The whole culture is understood as a set of concepts and relations between them.

N. Arutyunova offers to involve the semantics of a linguistic sign in the cognitive linguistics, which is the only means of forming the nature of the concept.

Thus, N. Arutyunova defines the concept as "the conceptual nature of language expressions" [Arutyunova, 1982]. The similar point of view is shared by N. Aliferenko, who claims that "the semantics of a language sign is the main source of the knowledge about the nature of the represented concept" [Aliferenko, 2001].

Supporters of one more approach to the definition of the concept are D. Likhachev and E. Kubryakova. They consider the concept to be the result of the collision of the meaning of the word with the personal experience of a person. It means that the concept is a mediator between words and reality. Giving the definition of the nature of the concept E. Kubryakova notes that the concept does not replace the whole word, but its individual dictionary meanings, so she defines the concept as an algebraic expression of the meaning that we use in written or oral speech, as each person interprets the meaning of the word in their own way depending on their education, personal experience, background and profession. The context and the situation of communication determine the dictionary meaning of the word [Kubryakova, 2004]. 
According to F. Keil, the concept is a term that serves to explain the units of mental resources of our consciousness and the information structure that reflects the knowledge and experience of a man. The concept is a meaningful unit of our memory of the conceptual system and the whole picture of the world reflected in the human psyche.

He also thinks that "concepts reduce a variety of observed and imaginary phenomena to something uniform, bringing them under one heading". They allow us to store knowledge about the world and are building elements, "contribute to the processing of our experience by summing up information under certain categories and classes developed by the society. Two or more different objects can be considered as copies and representatives of the same class/category" [Keil, 1989].

V. Karasik who is a representative of the linguocultural approach, characterizes the concepts as multidimensional, semantic formations in which the value, figurative and conceptual sides are distinguished [Karasik, 2002].

S. Vorkachev also defines the concept from the point of view of linguocultural approach and gives the following definition of the concept: "a unit of collective knowledge/consciousness (having the highest spiritual values), including a linguistic expression and marked by ethno-cultural specificity". If mental education has no ethno-cultural specificity, it does not belong to the category of concepts [Vorkachev, 2002, p. 33].

V. Krasnykh explores the concept from the point of view of psycholinguistics and linguoculturology and defines the concept as the most abstracted idea of a cultural object that does not have a visual prototype image, but there can be some visual-figurative associations [Krasnykh, 2003].

$\mathrm{V}$. Red gives the definition of the national concept. The national concept is the most general and abstracted, but it represents the linguistic consciousness, which is subjected to the cognitive processing of the idea of the subject [Red, 2003].

D.A. Cruse, a researcher in the field of lexical semantics of the language, developed the theory of the concept, which is based on the following bullet points:

1. each natural language has its own way of the world categorizing; the meanings form a single system imposed by the language on all speakers;

2. the way language perceives and arranges the world is partially universal and partially specific;

3. the way of conceptualization is "unique" because it is different from the scientific worldview, but these are not primitive representations [Cruse, 1986].

A. Vezhbitskaya, a researcher in the sphere of linguistic semantics, understands the concept as an object from the world "Ideal", having a name and reflecting the idea of the world "Reality". A. Vezhbitskaya takes into account a common base for the variety of ways of conceptualization of reality, found in different languages. In accordance with this approach, any complex concept can be presented in the form of a certain set of elementary meanings that are semantically universal. It means that they are present in all languages. A. Vezhbitskaya also introduced the terms of concept-maximum and concept-minimum. The concept-maximum is the knowledge of the meaning of the word, which is common for an ordinary native speaker. The concept-minimum is an incomplete understanding of the meaning, which, however, should not be below some limit [Vezhbitskaya, 2001].

M. Pimenova, a researcher in the field of the cognitive linguistics, notes that concepts are units of a conceptual system that contains information about the world. This information can be related to both the current and the virtual state of the world. "The concept is what a person knows, thinks, imagines about the objects of the outer and inner world. The concept is a representation of some part of the world" [Pimenova, 2004].

Z. Popova and I. Sternin are specialists in the field of the theoretical linguistics. They give the following definition of the concept: discrete mental phenomenon, which is the basic 
unit of the human mental code, having a relative internal structure, which is the result of cognitive (cognitive) activity of the individual and society and carrying a complex, encyclopedic information about an object or a phenomenon, the interpretation of this information by public consciousness and the attitude of public consciousness to this phenomenon or subject [Popova \& Sternin, 2007]. These scientists also offer to interpret concepts as units of thinking, not units of memory, as their main purpose is to provide the process of thinking. The authors note that not all concepts have a linguistic expression, there are many concepts that do not have a stable name. Many concepts are empirical. They believe that concepts do not require any ethnic and cultural specificity. As an example, the authors cite everyday concepts that do not have any ethno-cultural specificity. The authors believe that not all the concepts have a value component, for example, spatial and temporal concepts [Ibidem].

\section{THE STRUCTURE AND THE MODEL OF THE CONCEPT}

The concept is multidimensional, so different approaches are possible to determine its structure. In this paper we will consider linguocultural and cognitive approaches.

The concept has a complex structure, including, on the one hand, everything that relates to the content of the concept, and, on the other, features that make it a factor of the culture: etymology, modern associations, evaluation, and connotations. The structure of the concept is a set of generalized features and groups of features necessary and sufficient to identify an object or a phenomenon as a fragment of the world picture. As many linguists state (see, for example, [Malakhova, 2017]), these features do not reveal a strict sequence and are individual in nature, since their formation depends on the conditions of the formation of the concept itself for each individual person.

According to Trask, the concept consists of historical layers, different in time of formation, semantics and origin, and has a special structure, which includes a number of components:

- the most relevant;

- additional;

- an inner form (often does not exist in everyday life) [Trask, 1998].

V. Karasik based on the theory of the structure of the concept proposed by $\mathrm{Yu}$. Stepanov. He offers to consider different layers of the concept as separate concepts of different volumes:

- the active layer is a part of a nationwide concept;

- passive layers belong to separate subcultures;

- the inner form is not a part of the concept, but is one of the cultural elements that determine it.

According to V. Karasik, the center of the concept is always its value, and on this basis he identifies three components in the structure of the concept:

- value;

- factual (stored in the mind in verbal form and can be directly reproduced in speech);

- shaped (non-verbal, gives only the description) [Karasik, 1996].

Cruse considers the concept as a group mental complex, which includes not only the semantic content, but also the human attitude to the reflected object, its evaluation and other components:

- universal;

- cultural (associated with the human life in a particular cultural environment);

- social (determined by a person's belonging to a certain social layer);

- group (due to the belonging of a person to a certain age or sexual group); 
- individual (formed under the influence of education, education, individual experience).

From the point of view of cognitive linguistics, the concept has a multilevel and multilayered structure, and its nature can be described in terms of the core and periphery. The core is "a prototypical unit of the universal code, it can be both national and group and individual". He defines the core as "dictionary meanings of a certain lexeme" and the periphery as "subjective experience, various pragmatic components of a nuclear lexeme, connotations and associations". The core will include the primary brightest images with the most visual specificity, more abstract features make up the periphery of the concept [Cruse, 1986].

The concept has a certain organization: it consists of components (conceptual features) forming different conceptual layers. The level of abstraction of the value increases with each successive layer.

In any concept there is a base layer. It is a certain sensual image, which is a unit of the universal object code that encodes the concept for mental operations. If the concept reflects the specific feelings and perceptions, the base layer can exhaust the nature of the concept. In more complex concepts, additional features are added to the base layer, which can form relatively autonomous cognitive layers that reflect a certain result of cognition of the outside world and are structured from more specific to more abstract. The set of the base layer and additional cognitive layers form the scope of the concept.

Z. Popova and I. Sternin carried out three types of model concepts:

1. $\quad$ single-level - the concept includes only the core;

2. multilevel - the concept includes several cognitive layers that differ in the level of abstraction;

3. segmental - the concept contains a basic sensory layer surrounded by several segments equal in the degree of abstraction.

In the structure of the concept Z. Popova and I. Sternin distinguish three basic components - an image, an information content and an interpretation field.

The image in the structure of the concept is confirmed by the prototype semantics, which has been widely developed in the modern linguistics. Prototypes are images that represent a class of concepts. On the basis of the most important features of the prototype, the person carries out the categorization of the concept.

The prototype is also defined as the unit that exhibits the properties most common with other units of this group, as well as the unit that implements these properties completely.

The information content of the concept includes a minimum of cognitive features that determine the most important, distinctive features of the conceptualized object or phenomenon. These features characterize the main differential features of the subject, mandatory components, basic functions, etc., that is, determine the essence of the concept.

The interpretation field of the concept includes those features that in one aspect or another interpret the main nature of the concept, represent some kind of inference knowledge or evaluate it.

Z. Popova and I. Sternin consider the interpretation field as diverse and distinguish the following aspects:

1. evaluation aspect - combines cognitive features that reflect the assessment of the subject (General, aesthetic, emotional, intellectual, moral);

2. encyclopedic aspect - combines cognitive features that characterize the features of the concept that require familiarity with them on the basis of experience;

3. utilitarian aspect - combines cognitive features that Express a pragmatic attitude to the denotation of the concept, knowledge related to the possibility and features of its practical application; 
4. regulatory aspect - combines cognitive features, prescribing what is necessary and what is not to be done in the field defined by the concept;

5. socio-cultural aspect - combines cognitive features that reflect the relationship of the concept with the culture of the people;

6. paremiological aspect - a set of statements and ideas about the phenomenon reflected in the concept of national paroemia. Paroemias are folk sayings expressed by sentences (e.g. proverbs, sayings, signs), and short chains of sentences representing the basic scene or a simple dialogue (e.g. "simultaneous" jokes, riddles).

The interpretation field of the concept often contains contradictory cognitive features. It is explained by the fact that "conclusions" from different cognitive features are made in different conditions, in different historical periods, by different groups of native speakers. The interpretation field forms the periphery of the concept [Popova \& Sternin, 2007].

The nature and structure, the core and the periphery of the concept are studied to differentiate them in the process of studying, since their role and status in the structure of consciousness are different.

\section{THE DEFINITION OF "CONCEPT", "CONCEPTION" AND "MEANING"}

One of the directions of the cognitive linguistics is the study of the conceptual sphere the phenomenon of the mental world, the set of views of all the people and each individual on reality, which are found in the minimal units - concepts. Such terms as "concept", "conception" and "meaning" are often regarded as equivalents. The word "concept" is the same as the Latin word "conceptus". Scientists" opinions differ in the definition of the term "concept", so there are many definitions in linguistics. The cognitive psychology separates the concept from the conception, so these terms are now quite clearly distinguished.

The concept and the conception are terms of different sciences. The term "conception" is used in logic and philosophy and the concept acts as a term of mathematics and cultural studies. The concept is one of the key phenomena in modern cognitive linguistics. The term "concept" is currently widely used in many Humanities. The analysis of linguistic sources testifies to the ambiguous attitude of linguists to the understanding of the terms "concept" and "conception". The term "concept", as well as the term "conception", reflects the form of the vital reality of the human psyche. However, the concept also expresses the emotional reflection, in addition to the rational representation of the world. In this aspect the terms "concept" and "conception" do not always coincide in their structure.

Conceptions have a simpler structure, whereas there are more components in the structure of the concept. The concept, in contrast to the conception, includes not only the essential and necessary features, but also non-essential ones. The concept expresses not only the set of features of the object, but also those ideas, knowledge, associations, experiences that are associated with it. Thus, the difference between the concept and the conception is obvious. The concept reflects only the most common and significant features of objects and phenomena.

The terms concept and conception are historically similar. In modern scientific and nonscientific researches these terms are different. Moreover, the contrast of these two terms - the concept and the conception - is the basis of a new semantic dictionary by N. Shvedova: the concept is the content feature of the verbal sign, which is the idea that fixes the essential "intelligible" properties of realities and phenomena, as well as the relationship between them. It belongs to the mental, spiritual or vital spheres of human existence, developed and consolidated by the social experience of the people, which has historical roots in our life. It is socially interpreted and correlated with other concepts associated with it or in many cases 
opposed to it. The definition of the concept has its own value. It is a reflection of the ability to form a variety of verbal shifts.

This definition of the concept can be adopted in relation to those units that in the literature are called "large" or "great", "basic" concepts. It must be noted that such "basic" concepts are surrounded by accompanying units - "small", "non-basic", concepts, which often lack some of the above features, such as the obligation of deep historical roots, the traditional designation; in "small" concepts the subjective assessment of opposition or comparison with other units can be omitted. Such small concepts with a "flawed" system of conceptual features do not, however, fall out of the scope of the basic concept: they create the environment without which the concept can not exist [Shvedova, 2005].

I. Susov and A. Susov compare the concept "dog" and the conception "dog" and specified certain characteristics of the concept "dog": animal, vertebrate, mammal, canine, viviparous, domesticated. The conception "dog" has fewer components, such as barking, having a tail, being able to bite.

The concept has an emotional and expressive colouring; the term is associated with different concepts, imaginations and knowledge. Unlike the concept that passes through the individual consciousness, the concept requires complex means of expression: emotions, likes, dislikes and sometimes even collisions.

The conception represents a set of basic cognized features of the object, and the conception is a mental unit of the worldview containing linguistic and cultural knowledge, representation and evaluation. Phraseological, lexical and other linguistic means express the concept in different ways. If we recognize the concept as a sign of linguistic knowledge, it may well reflect a mental beginning that has a close connection with the word [Susov \& Susov 2003].

According to M. Johnson the notion of "meaning" is not an insistence on a single unified literal concept "meaning"; rather it is a commitment to the existence of a series of connections among the various senses of means. Meaning is always a matter of relatedness (as a form of intentionality) [Johnson, 1990].

Thus, the problem of difference between the concept, the meaning and the conception is still an urgent and necessary issue of the modern linguistics. By comparing the basis, content and scope of the concept, the conception and the meaning, one can determine their difference. The conception is allocated in the logical way, and the concept is shown in the form of sublogical formations. The conception is understood as the meaning that exists regardless of national features, it is expressed by logical thinking. The concept is more diverse. The concept is a mentally national phenomenon, a complex of human values and human experience.

\section{THE PLACE OF THE SIGN, VALUE, AND CONCEPT IN LINGUISTICS}

It is well known that the concept is expressed by a sign. That's why many questions arise: what is a primary thing: a sign or a concept? Does every word have its own concept? If every word has a concept, then how many concepts does a polysemic word have? What is the correlation between one concept and several words?

According to the scientific point of view, the sign is primary in relation to the concept. The concept by its nature is analyzed in the context of other phenomena. If we understand the meaning of the word by its context, the concept is understood in the context of culture. Thus, the concept is studied by means of proverbs, sayings, idioms and clichés. In addition, not all the words that express some phenomenon can act as concepts. Considering the essence of the concept the researchers emphasize its belonging to the human culture. The content of the concept is the representation of the cultural pattern of the nation. 
The meaning of the concept and the meaning of the word is one of the burning issues of modern linguistics. The concept and the meaning of the word can be studied by linguistics, logic, psychology, semiotics and philosophy. Each of them has its own system of terminology. Modern science considers the dichotomy of the concept and the meaning as the ratio of cognitive thinking and semantic phenomenon. Thus, the concept and meaning of the word have the same cognitive nature. Both phenomena reflect objective and subjective reality.

There are many different interpretations of the relationship between the concept and the meaning of the word, which leads to disagreements among researchers. We can identify three different main areas of the study of this problem. Yu. Stepanov notes that the concept is like a coherence of culture in the human consciousness. It is the form which culture takes to become of the mental world of a person.

The second school of the scientific thought (N. Arutyunova, T. Bulygina, A. Shmelev) believes that the semantics forms the concept.

Supporters of the third school (D. Likhachev, E. Kubryakova) believe that the concept does not arise directly from the meaning of the word, but it is the result of a collision of the meaning with the national and personal experience of a native speaker [Kubryakova, 2004].

Thus, the concept acts as a mediator between the word and the reality. The concept represents the whole potential of the word meaning, at the same time it contains the whole complex of associative imaginations. It is very important to understand the difference between the concept and the meaning of the word (sememe). The meaning is a part of the concept, it represents a narrow sense. However, the meaning is a reflection of objects and phenomena in our consciousness, which is expressed by the inner meaning of the structure of the word. The relationship between the concept and the meaning of the word is very important, as it affects both the definition of the subject of cognitive linguistics and the development of methods for the analysis of the semantics of the language. The concept is the product of cognitive human consciousness; the value is the product of language consciousness. The meaning (sememe) forms a concept, but it is only a part of the semantic nature of the concept. The components of the lexical meaning can convey the basic conceptual features. The concept is wider than the lexical meaning of the word. The structure of the concept is much more complex and multifaceted than the lexical meaning of the word.

Cognitive features of the meaning form the nature of the concept. The meaning of the word also has some kind of a cognitive character - it consists of sememes representing the individual cognitive characteristics that form the nature of the concept in speech.

To interpret the entire nature of the concept, we need numerous lexical units. It means the semantics of many words. When considering the problem of terminological differentiation, it is necessary to take into account that the concept is the unit of the conceptual sphere, the value is the unit of the semantic sphere of the language.

\section{CONCLUSION}

We have considered a variety of approaches and options for the definition of the concept. In our paper, we rely on the definition of the concept given by Z. Popova and I. Sternin, who consider the concept as a basic mental formation with an ordered structure, and which is the result of cognitive activity of a person or a society. It contains information about the reflected object or phenomenon and how this information interprets public consciousness. After analyzing all the main approaches to the study of concepts in Russian and foreign literature the conclusion is as follows: not all concepts in professional communication have a linguistic expression, many concepts are empirical in nature. Concepts do not require an ethnocultural specificity, but basic cognized features of all concepts have a value component. 


\section{REFERENCE}

1. Alefirenko, N.F. (2005). Sovremennye problemy nauki o jazyke: uchebnoe posobie [Modern problems of the language science]. Moscow: Flinta: Nauka (in Russian).

2. Arutyunova, N.D. (1982). Lingvisticheskie problemy referencii [Linguistic problems of reference]. Novoe $v$ zarubezhnoj lingvistike [New in foreign linguistics], 13, 5-40 (in Russian).

3. Cruse, D.A. (1986). Lexical semantics. Cambridge University Press.

4. Geeraerts, D. (2007). The Oxford handbook of cognitive linguistics. Oxford University Press.

5. Johnson, M. (1990). The body in the mind. The bodily basis of meaning, imagination, and reason. University of Chicago Press.

6. Karasik, V.I. (2002). Jazykovoj krug: lichnost', koncepty, diskurs [Language circle: personality, concepts, discourse]. Volgograd: Peremena (in Russian).

7. Keil, F.C. (1989). Concepts, kinds, and cognitive development. Cambridge: MIT Press.

8. Kubryakova, E.S. (2004). Jazyk i znanie: Na puti poluchenija znanij o jazyke: Chasti rechi $\mathrm{s}$ kognitivnoj tochki zrenija. Rol' jazyka v poznanii mira [Language and knowledge: on the way to gain knowledge of the language: parts of speech from the cognitive point of view. The role of language in the knowledge of the world]. Moscow: Languages of Slavic culture (in Russian).

9. Lakoff, G., \& Johnson, M. (1980). Metaphors we live by. University of Chicago Press.

10. Malakhova, V.L. (2017). Tipy frazeologicheski reprezentiruemyh konceptov v anglijskom jazyke [Types of phraseologically represented concepts in English]. Nauchnye Vedomosti BelGU. Serija Gumaniratnye nauki [Scientific journal of Belgorod State University. Ser. Human sciences], No 7(256), Issue 33, 65-75 (in Russian).

11. Pimenova, M.V., \& Kondratieva, O.N. (2006). Konceptual'nye issledovanija. Vvedenie [Introduction to the conceptual studies: a tutorial]. Kemerovo: Kuzbassvuzizdat (in Russian).

12. Popova, Z.D, \& Sternin, I.A. (2007). Kognitivnaja lingvistika [Cognitive linguistics]. Moscow: AST: East-West (in Russian).

13. Red, V. (2003). "Native” among "strangers": myth or reality? Moscow: IDGC Gnosis.

14. Shvedova, N.Yu. (2002). Tolkovyj slovar', sistematizirovannyj po klassam slov i znachenij [Explanatory dictionary systematized by classes of words and meanings]. Moscow: Russian Academy of Sciences. Russian Language Institute (in Russian).

15. Susov, I.P. Susov, A.A. (2003). Ponjatie vs. koncept [Meaning vs. concept]. Tverskoj lingvisticheskij meridian [Tver Linguistic Meridian], 4, 3-10 (in Russian).

16. Telia, V.N. (1996). Russkaja frazeologija. Semanticheskij, pragmaticheskij i lingvokul'turologicheskij aspekty [Russian phraseology. Semantic, pragmatic and linguocultural aspects]. Moscow: School "Languages of Russian culture" (in Russian).

17. Trask, R.L. (1998). Key concepts in language and linguistics. London, New York.

18. Vezhbitskaya, A. (2001). Ponimanie kul'tur cherez posredstvo kljuchevyh slov [Understanding cultures through key words]. Moscow: Languages of Slavic culture (in Russian).

19. Vorkachev, S.G. (2007). Ljubov' kak lingvokul'turnyj koncept [Love as a linguocultural concept]. Moscow: Gnosis (in Russian). 